\title{
Development of the Motivation to Change Lifestyle and Health Behaviours for Dementia Risk Reduction Scale
}

\author{
Sarang Kim Kerry Sargent-Cox Nicolas Cherbuin Kaarin J. Anstey \\ Centre for Research on Ageing, Health and Well-Being, Australian National University, \\ Canberra, A.C.T., Australia
}

\section{Key Words}

Behaviour change $\cdot$ Dementia risk reduction $\cdot$ Scale development $\cdot$ Lifestyle change

\begin{abstract}
Background and Aims: It is not yet understood how attitudes concerning dementia risk may affect motivation to change health behaviours and lifestyle. This study was designed to develop a reliable and valid theory-based measure to understand beliefs underpinning the lifestyle and health behavioural changes needed for dementia risk reduction. Methods: 617 participants aged $\geq 50$ years completed a theory-based questionnaire, namely, the Motivation to Change Lifestyle and Health Behaviours for Dementia Risk Reduction (MCLHB-DRR) scale. The MCLHB-DRR consists of 53 items, reflecting seven subscales of the Health Belief Model. Results: Confirmatory factor analysis was performed and revealed that a seven-factor solution with 27 items fitted the data (comparative fit index $=0.920$, root-mean-square error of approximation $=0.047$ ) better than the original 53 items. Internal reliability $(\alpha=0.608-0.864)$ and test-retest reliability ( $\alpha=0.552-0.776)$ were moderate to high. Measurement of invariance across gender and age was also demonstrated. Conclusions: These results propose that the MCLHB-DRR is a useful tool in assessing the beliefs and attitudes of males and females aged $\geq 50$ years towards dementia risk reduction. This measure can be used in the development and evaluation of interventions aimed at dementia prevention.

(c) 2014 S. Karger AG, Basel
\end{abstract}

\section{Introduction}

It is well understood that individuals can make major contributions to their own health and wellbeing through the adaptation of health-enhancing behaviours (e.g., exercising) and the avoidance of health-compromising behaviours (e.g., smoking and excessive alcohol consumption) [1]. In the past few decades, research has focused on the identification of health behaviours that contribute to disease and on interventions designed to improve health behaviours [2,3]. 
Of specific interest here, research has identified numerous lifestyle factors that play a major role in reducing the risk of dementia. It is now well recognized that participating in cognitively stimulating leisure activities [4], regular physical activity [5-8], a Mediterraneantype diet $[9,10]$, and a moderate alcohol intake [11] are all associated with a lower incidence of dementia, whereas smoking [12], diabetes [13], mid-life high cholesterol [14], excessive alcohol consumption [15], depression [16], and mid-life obesity [17, 18] are associated with a higher risk of dementia. Moreover, combination of behaviours targeting multiple risk factors may reduce the risk of dementia better than targeting a single risk factor. Barnes and Yaffe [19] argued that 1.1-3.0 million Alzheimer's disease cases can be prevented worldwide by a 10-25\% reduction in seven risk factors (diabetes, midlife hypertension, midlife obesity, smoking, depression, cognitive inactivity, and physical inactivity).

Nevertheless, reduction of dementia prevalence cannot be achieved by the identification of risk factors alone. What is needed are theoretically and empirically driven interventions targeting optimisation of the known health behaviours and lifestyle. There are three large ongoing dementia prevention studies in Europe: the Prevention of Dementia by Intensive Vascular Care (PreDIVA, ISRCTN 29711771) study; the Finnish Geriatric Intervention Study to Prevent Cognitive Impairment and Disability (FINGER, NCT01041989), and the Multidomain Alzheimer Preventive Trial (MAPT, NCT00672685) [20]. In addition, there are limited numbers of randomised controlled trials, which have shown positive but weak to moderate effects of physical exercise and cognitive training on cognition [21-24]. Although these results may not be conclusive and require extensive further research, there is mounting evidence from observational studies that point to the importance of reducing these risk factors for dementia prevention.

Behavioural change theories provide a helpful basis for the design of interventions to change lifestyle and health behaviours through the understanding of structural and psychological determinants of behaviours [25, 26]. Within a health behaviour change model, successful interventions designed to address dementia risk behaviours include addressing attitudes and beliefs surrounding health and lifestyle behaviours and dementia risk in the population. We are, however, unaware of any studies using a behavioural change model as a theoretical framework that examines attitudes regarding motivation for behaviour and lifestyle changes for the prevention of dementia. Therefore, the development of a scale examining the motivations and beliefs surrounding behavioural and lifestyle change specifically for dementia risk reduction is needed.

In the current study, the Health Belief Model (HBM) is used as a conceptual model to develop a measurement of motivation for behavioural and lifestyle change for dementia risk reduction for middle-aged and older Australians. The HBM is one of the most commonly used theories explaining health-related behaviours and health promotion $[27,28]$. The premise of the HBM is that the identification of beliefs and motivations related to health behaviours can inform the development of interventions designed to increase desirable health behaviours [29]. This model was initially introduced with four main concepts: perceived susceptibility, perceived seriousness/severity, perceived benefits, and perceived barriers [30, 31]. Three additional concepts, cues to action, general health motivation, and confidence (self-efficacy), were later added to the original HBM to enrich the model and to address some criticism of the earlier model of the HBM [32]. Such criticism was that (1) health behaviours are not always rational; (2) HBM only focuses on the individual and ignores social and environment factors; (3) the role of emotional factors is not duly considered, and (4) alternative factors may predict health behaviour, such as outcome expectancy and self-efficacy [33, 34]. Although introducing these three additional components to the HBM does not address all its weaknesses, the HBM with seven concepts was chosen as the best-suited model for dementia risk reduction after careful consideration of six different behaviour change models (HBM, Health Locus of 
Kim et al.: Development of the Motivation to Change Lifestyle and Health Behaviours for Dementia Risk Reduction Scale

Control, Theory of Reasoned Action/Theory of Planned Behaviour, Self-efficacy Theory, stage of change/Transtheoretical Model of Change, and common sense model of self-regulation) against the outcome of a qualitative study [35].

According to the HBM, a health-promoting behaviour is more likely to occur if the individual feels threatened by her/his current behavioural patterns through perceived susceptibility and severity, and believes that a specific behavioural change will result in a valued outcome at acceptable cost where perceived benefits outweigh perceived barriers. Moreover, an internal or external stimulus to change behaviours (cues to action), desire to achieve an outcome (general health motivation), and confidence in being able to perform the desired behaviours (self-efficacy) are needed [46].

The HBM has not been applied to the examination of behavioural changes for dementia risk reduction specifically. However, a small number of studies have used the HBM to understand the intention to undergo a cognitive status examination for dementia and memory loss and have shown that factors from the HBM (especially perceived barriers and cues to action) were significant predictors of intention [36, 37].

The purpose of this study is to develop and evaluate a new instrument, namely the Motivation to Change Lifestyle and Health Behaviour for Dementia Risk Reduction (MCLHB-DRR) scale, designed to assess beliefs and attitudes about lifestyle and health behavioural changes for dementia risk reduction among middle-aged and older Australians.

\section{Methods}

\section{Development of the MCLHB-DRR Scale}

The items included in the MCLHB-DRR were constructed based on focus group interviews conducted with 34 middle-aged and older Australians [38] and by modifying items from the existing literature on the HBM applied to breast cancer screening [30] and cognitive status examination [36]. The scale included seven subscales that reflected the seven concepts of the HBM: perceived susceptibility (participants' perceived risk for developing dementia during their lifetime); perceived severity (how anxious and stressed they would feel if they developed dementia); perceived benefits (participants' perceptions regarding possible benefits associated with changing lifestyle and health behaviour to reduce dementia risk); perceived barriers (participants' perceptions regarding possible barriers associated with changing lifestyle and health behaviour to reduce dementia risk); cues to action (participants' perceptions regarding the social influence to change lifestyle and health behaviour for dementia risk reduction); general health motivation (how much they value their general health and wellbeing), and self-efficacy (confidence in changing lifestyle and health behaviour for dementia risk reduction), comprising 53 items. All items were rated on a 5-point Likert scale from 1 (strongly disagree) to 5 (strongly agree).

The HBM typically predicts one specific type of health behaviour. However, multi-domain interventions may be more effective than single-domain interventions in dementia prevention [19]. Therefore, any health behaviour and lifestyle that individuals are engaged in to reduce their risk of developing dementia should be considered as a dementia-preventing behaviour. These behaviours include participating in cognitively stimulating leisure activities; participating in regular physical activity; drinking at light to moderate levels; quitting smoking; maintaining body mass index within the normal range; increasing fish consumption, and engaging in high level of social engagement.

Before the questionnaire was distributed to the participants, the 53 items, prepared by the first author, were assessed for their clarity of expression and content validity by all investigators. Minor revisions (rephrasing of items) were made based on this process. 
Kim et al.: Development of the Motivation to Change Lifestyle and Health Behaviours for Dementia Risk Reduction Scale

Table 1. Characteristics of the sample (given in percentages)

\begin{tabular}{|c|c|c|c|c|c|c|}
\hline \multirow[t]{2}{*}{ Characteristics } & \multicolumn{3}{|c|}{ Male age groups, years } & \multicolumn{3}{|c|}{ Female age groups, years } \\
\hline & $\begin{array}{l}50-59 \\
(n=85)\end{array}$ & $\begin{array}{l}60-69 \\
(n=118)\end{array}$ & $\begin{array}{l}\geq 70 \\
(n=46)\end{array}$ & $\begin{array}{l}50-59 \\
(n=197)\end{array}$ & $\begin{array}{l}60-69 \\
(n=136)\end{array}$ & $\begin{array}{l}\geq 70 \\
(n=35)\end{array}$ \\
\hline Marital status: married/de facto & 62.4 & 72.9 & 87.0 & 69.5 & 60.3 & 48.6 \\
\hline High school education & 41.2 & 28.0 & 28.3 & 49.7 & 52.9 & 42.9 \\
\hline Currently working & 51.8 & 28.8 & 4.3 & 47.7 & 21.3 & 2.9 \\
\hline Income <AUD 52,000 & 50.6 & 60.2 & 78.3 & 53.8 & 80.1 & 74.3 \\
\hline Born in Australia & 82.4 & 75.4 & 71.7 & 78.7 & 68.4 & 65.7 \\
\hline \multicolumn{7}{|l|}{ Area of residency } \\
\hline Australian Capital Territory & 1.2 & 0 & 0 & 1.5 & 0.7 & 0 \\
\hline New South Wales & 22.6 & 36.8 & 40.0 & 33.7 & 33.3 & 42.9 \\
\hline Victoria & 33.3 & 23.1 & 22.2 & 23.0 & 23.0 & 17.1 \\
\hline Queensland & 21.4 & 23.1 & 17.8 & 26.0 & 17.0 & 17.1 \\
\hline South Australia & 13.1 & 7.7 & 8.9 & 6.6 & 12.6 & 5.7 \\
\hline Western Australia & 4.8 & 7.7 & 8.9 & 4.1 & 9.6 & 14.3 \\
\hline Northern Territory & 2.4 & 0 & 0 & 0 & 0 & 0 \\
\hline Tasmania & 1.2 & 1.7 & 2.2 & 5.1 & 3.7 & 2.9 \\
\hline Relatives/friends with dementia & 38.8 & 52.5 & 58.7 & 46.2 & 53.7 & 54.3 \\
\hline Cared for relatives/friends with dementia & 11.8 & 17.8 & 23.9 & 16.2 & 23.5 & 11.4 \\
\hline
\end{tabular}

\section{Participants and Data Collection}

A total of 659 Australians, recruited through the survey company Qualtrics (www. qualtrics.com), took part in an online survey on motivations to change health and lifestyle behaviours for dementia risk reduction. The criteria for inclusion were a minimum age of 50 years and not having previously been diagnosed with dementia. Forty-two individuals who did not agree with the terms and hence did not give their consent to participate in the study and those who were under 50 years of age were not included, leaving 617 subjects for data analysis. The study was approved by the Australian National University Ethics Committee, and all participants provided written informed consent to participate.

On the website, participants were required to read an information sheet and approve a consent form before proceeding to the questionnaire. The sociodemographics questionnaire (age, gender, education level, marital status, employment status, and income level) was given prior to the completion of the MCLHB-DRR.

The participants ranged in age from 50 to 96 years (males $=61.08, \mathrm{SD}=7.61$ ), and $59.6 \%$ of the total participants were female. The majority of participants were married or in de facto relationships (67.3\%), lived in New South Wales (33.7\%), had a secondary school education (43.1\%), and were retired (45.4\%). A total of 305 individuals (49.4\%) also reported that they had relatives or friends who suffer/suffered from dementia, and $110(17.8 \%)$ cared for a relative or friend with dementia. See table 1 for more detailed demographics.

To examine the test-retest reliability of the questionnaire, a random subsample from the original 617 participants $(n=108)$ was asked to return to the survey website within approximately 3 weeks to complete the questionnaire again. Participants had provided consent to being recontacted at the start of the study.

\section{Data Analysis}

As the scale was theory driven and developed based on pre-existing conceptual findings from our qualitative study and literature, pre-determined categories or grouping of the items were used. To validate and refine this structure, a series of confirmatory factor analyses (CFA) were conducted. We allowed for improvements and modifications in the form of error covari- 
Table 2. GFI for MCLHB-DRR models

Kim et al.: Development of the Motivation to Change Lifestyle and Health Behaviours for Dementia Risk Reduction Scale

\begin{tabular}{|c|c|c|c|c|c|}
\hline & \multicolumn{5}{|c|}{ GFI indices } \\
\hline & $\chi^{2}$ & d.f. & GFI & CFI & RMSEA \\
\hline Model 1 & $5,810.62$ & 1,682 & 0.713 & 0.668 & 0.063 \\
\hline Model 2 & 718.65 & 302 & 0.916 & 0.920 & 0.047 \\
\hline
\end{tabular}

ances and removal of poor performing items (i.e., low factor loading of a value below 0.45 or significant cross-loading) [39] to maximize future use of the scale and minimize participant burden. Items were permitted to load only on the construct they theoretically represented. Error covariances identified by modification indices were only examined further if (a) they would reduce large residuals and significantly improve the fit of a poor fitting model and (b) made theoretical or conceptual sense.

We used the following multiple fit indices to evaluate the model fit: the $\chi^{2}$ (and the respective degrees of freedom, d.f.), goodness of fit index (GFI), comparative fit index (CFI), and root-mean-square error of approximation (RMSEA). The CFI and GFI values between 0.90 and 0.95 or above suggest a good to excellent fit [40-42], and RMSEA values of $p<0.05$ suggest a good model fit [43].

Reliability and internal consistency for each subscale were assessed using correlation analyses (Cronbach's alpha and item-total correlation), and the stability of the measures was examined through test-retest reliability assessment via intra-class correlation coefficients. Construct validity was not evaluated due to unavailability of a similar measurement to the MCLHB-DRR.

To examine whether the scores obtained from the MCLHB-DRR are generalizable between age and gender, tests of measurement invariance were conducted. Data were analysed with SPSS and AMOS version 20.

\section{Results}

\section{Confirmatory Factor Analyses}

Two models (table 2) were tested, and the first model was a seven-factor model in which all 53 items were used. The analysis showed that this model was not a good fit of the data. All fitted indices were less than the accepted value of 0.9 (CFI $=0.668, \mathrm{GFI}=0.713$ ). The RMSEA (0.063) was also outside the accepted value of 0.05 or less.

The second model (fig. 1) was a seven-factor model using the 27 remaining items (see Appendix A) after deleting items demonstrating low correlations with their respective scales (value below 0.45 ) and items loading on more than one factor. This model resulted in a better fit than the first model, with all fit indices being larger than 0.90 (GFI $=0.916$, CFI $=0.920$ ) and smaller than 0.05 (RMSEA $=0.047) \cdot \chi^{2}$ was 718.6 (d.f. $\left.=302, p=0.000\right)$. The standardized coefficients of the perceived susceptibility items (4 items), perceived severity (5), perceived benefits (5), perceived barriers (4), cues to action (4), general health motivation (4), and selfefficacy (2) ranged from 0.366 to 0.852 and were all statistically significant $(p<0.001)$. The correlations between factors were statistically significant for most factors (table 3 ).

\section{Reliability and Internal Consistencies}

Correlation analyses were conducted using the 27 items from the second CFA. Correlation analysis indicated that all item scores were positively correlated with the total scale score. The correlation coefficients ranged from 0.743 to 0.875 ( $p<0.01$ for all) for perceived 


\section{Ex X T R A A \\ Dementia \\ and Geriatric}

Cognitive Disorders

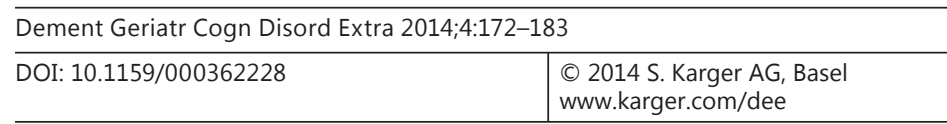

Kim et al.: Development of the Motivation to Change Lifestyle and Health Behaviours for Dementia Risk Reduction Scale

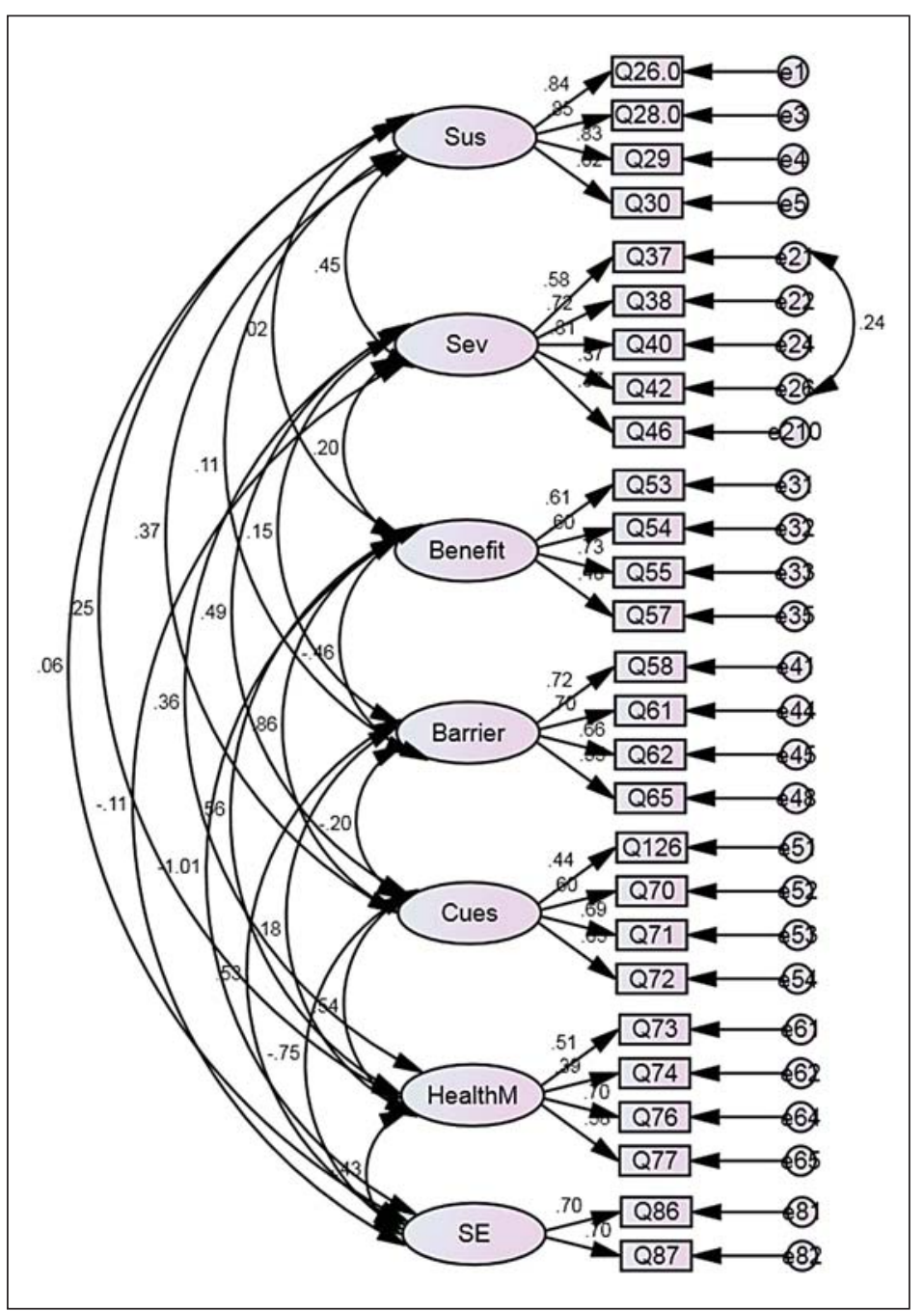

Fig. 1. CFA model with 27 items. Sus (perceived susceptibility), Sev (perceived severity), Benefit (perceived benefit), Barrier (perceived barrier), Cues (cues to action), Health M (general health motivation), SE (self-efficacy). 
Table 4. Reliabilities for subscales

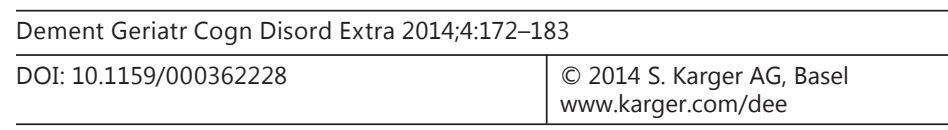

Kim et al.: Development of the Motivation to Change Lifestyle and Health Behaviours for Dementia Risk Reduction Scale

\begin{tabular}{llll}
\hline Subscales & $\begin{array}{l}\text { No. of } \\
\text { items }\end{array}$ & $\begin{array}{l}\text { Cronbach's } \\
\text { alpha }\end{array}$ & $\begin{array}{l}\text { Test- } \\
\text { retest }\end{array}$ \\
\hline Perceived susceptibility & 4 & 0.864 & 0.776 \\
Perceived severity & 5 & 0.725 & 0.726 \\
Perceived benefits & 4 & 0.694 & 0.645 \\
Perceived barriers & 4 & 0.740 & 0.651 \\
Cues to action & 4 & 0.684 & 0.552 \\
General health motivation & 4 & 0.608 & 0.596 \\
Self-efficacy & 2 & 0.658 & 0.602 \\
\hline
\end{tabular}

Table 5. Results of the measurement invariance tests

\begin{tabular}{|c|c|c|c|c|c|c|c|}
\hline Model description & $\chi^{2}$ & d.f. & $\Delta \chi^{2}$ & $\Delta$ d.f. & $\begin{array}{l}\text { Statistical } \\
\text { significance }\end{array}$ & CFI & $\Delta \mathrm{CFI}$ \\
\hline \multicolumn{8}{|l|}{ Gender } \\
\hline Configural model (no equality constraints imposed) & $1,077.8$ & 604 & - & - & - & 0.910 & - \\
\hline Measurement model (all factor loadings constrained equal) & $1,112.1$ & 631 & 34.3 & 27 & n.s. & 0.910 & 0.000 \\
\hline \multicolumn{8}{|l|}{ Age } \\
\hline Configural model (no equality constraints imposed) & $1,095.2$ & 604 & - & - & - & 0.908 & - \\
\hline Measurement model (all factor loadings constrained equal) & $1,114.2$ & 625 & 19 & 21 & n.s. & 0.908 & 0.000 \\
\hline
\end{tabular}

susceptibility, from 0.606 to 0.752 for perceived severity, from 0.648 to 0.787 for perceived benefits, from 0.728 to 0.796 for perceived barriers, from 0.642 to 0.765 for cues to action, from 0.589 to 0.779 for general health motivation, and from 0.861 to 0.866 for self-efficacy. The Cronbach alpha values ranged from 0.608 to 0.864 (table 4) for general health motivation and perceived susceptibility, respectively, showing good internal consistency.

Test-retest reliability was evaluated with a representative subset of the original sample (108 subjects) approximately 3 weeks later. The retest participants did not significantly differ from the remaining members of the sample on demographic factors or any other variables examined in this study. The factor scores demonstrated moderate test-retest reliabilities for all subscales, and the Cronbach alpha values ranged from 0.552 to 0.776 (table 4).

\section{Gender and Age Differences}

Tests of measurement invariance were performed to examine the generalizability of the MCLHB-DRR across gender and age groups. Traditionally, the $\Delta \chi^{2}$ has been used as the index of difference in fit. However, because $\Delta \chi^{2}$ has been found to be overly sensitive to sample size, Cheung and Rensvold [47] recommended using $\Delta$ CFI with values higher than 0.01 as an indication of measurement invariance not being found.

The results from measurement invariance tests indicated that the fit of this model to be consistent with that of the configural model for both gender and age groups (50-64 years old: pre-retirement, and 65 years and over: post-retirement; table 5). Both $\Delta \chi^{2}$ and $\Delta$ CFI argued for invariance where the differences were not statistically significant.

In addition, a table describing the means for each subscale for the MCLHB-DRR across different gender and age groups is recorded in table 6 . Males who were $50-59$ years old had significantly higher levels of perceived susceptibility $(\mathrm{p}=0.036)$ and perceived barriers $(\mathrm{p}=$ 0.022 ) than 70-year-old and older males. Males who were 50-59 years old also had significantly higher levels of health motivation than 60-69 years old males ( $\mathrm{p}=0.014)$. On the other hand, no significant age difference was shown in females. 
Table 6. Results of the MCLHB-DDR subscales for the different age and gender groups

\begin{tabular}{|c|c|c|c|c|c|c|}
\hline & \multicolumn{3}{|c|}{ Male age group, years } & \multicolumn{3}{|c|}{ Female age group, years } \\
\hline & $50-59$ & $60-69$ & $\geq 70$ & $50-59$ & $60-69$ & $\geq 70$ \\
\hline Perceived susceptibility & $11.2 \pm 2.3(4-17)$ & $10.9 \pm 2.6(4-19)$ & $10.1 \pm 2.0(4-15)$ & $10.7 \pm 2.9(4-19)$ & $11.2 \pm 2.8(4-18)$ & $10.3 \pm 2.1(6-15)$ \\
\hline Perceived severity & $14.9 \pm 2.9(9-24)$ & $14.9 \pm 3.3(5-25)$ & $14.7 \pm 3.0(5-20)$ & $15.7 \pm 3.3(7-25)$ & $16.1 \pm 3.5(7-24)$ & $15.5 \pm 2.6(11-22)$ \\
\hline Perceived benefits & $13.8 \pm 2.5(4-20)$ & $14.0 \pm 2.1(9-20)$ & $13.4 \pm 1.8(7-18)$ & $14.1 \pm 1.9(8-19)$ & $14.3 \pm 2.3(7-20)$ & $14.6 \pm 2.5(9-20)$ \\
\hline Perceived barriers & $10.5 \pm 2.9(4-20)$ & $9.8 \pm 2.3(4-15)$ & $9.2 \pm 2.2(4-13)$ & $10.1 \pm 2.6(4-20)$ & $9.5 \pm 2.5(4-17)$ & $9.2 \pm 2.4(5-14)$ \\
\hline Cues to action & $12.4 \pm 2.5(4-20)$ & $12.2 \pm 2.2(8-18)$ & $11.5 \pm 2.6(4-16)$ & $12.5 \pm 2.2(7-19)$ & $12.5 \pm 2.3(5-18)$ & $12.3 \pm 2.3(7-16)$ \\
\hline Health motivation & $15.0 \pm 2.6(4-20)$ & $15.9 \pm 2.1(10-20)$ & $15.4 \pm 2.1(11-20)$ & $15.3 \pm 2.2(9-20)$ & $15.7 \pm 2.1(10-20)$ & $15.7 \pm 2.1(12-20)$ \\
\hline Self-efficacy & $5.3 \pm 1.2(2-8)$ & $5.1 \pm 1.3(2-8)$ & $5.3 \pm 1.4(2-8)$ & $5.1 \pm 1.3(2-10)$ & $54.0 \pm 1.3(2-9)$ & $4.6 \pm 1.4(2-9)$ \\
\hline
\end{tabular}

Values are presented as means \pm SD (ranges).

\section{Discussion and Conclusions}

This study describes the development and evaluation of the psychometric properties of a new scale (MCLHB-DRR) designed to understand beliefs and motivations of behaviours to reduce dementia risk for middle-aged and older Australians. The seven-factor model reflected dimensions of the HBM (perceived susceptibility, perceived severity, perceived benefits, perceived barriers, cues to action, general health motivation, and self-efficacy) on lifestyle and health behavioural changes for dementia risk reduction.

The CFA showed a model with 27 (of the original 53) items as the best fit for the data, demonstrating the soundness of the psychometric properties of the MCLHB-DRR, and the suitability of the HBM in characterizing beliefs and motivations regarding behavioural and lifestyle changes critical for dementia risk reduction. The internal consistencies for the seven subscales were moderate to high, and the test-retest reliability for the scale was moderate after an approximate 3-week interval. Lower test-retest reliability can be due to fluidity of the beliefs as MCLHB-DRR measures a construct of values that can change with experiences or knowledge. The findings also indicated that all items designed to measure motivation to change lifestyle and health behaviours for dementia risk reduction are operating equivalently across the two groups of age and gender.

One interesting finding from this study was that three of the five final perceived severity items were emotionally driven items that address fear (the thought of dementia scares me; when I think about dementia my heart beats faster, and when I think about dementia I feel nauseous). This is in contrast to the construct of the initial items (from the original 53-item scale) that addressed perceived severity of developing dementia in terms of its relation to finance, relationship, and other effects on the individual. However, having these emotionally driven items was not a surprise, as in 2010, Pfizer reported that almost two of three Australians (63\%) over the age of 18 years feared developing dementia. This suggests that the fear of developing dementia may be a motivating factor for health and lifestyle behavioural changes, and this can be examined closely in future research. However, the items for other subscales were all in line with the typical HBM construct in that individuals are likely to change lifestyle and health behaviour if they believe that (1) they have a high chance of developing dementia; (2) they will benefit from changing lifestyle and health behaviours; (3) they have few barriers; (4) they have internal and/or external cues to change; (5) they value general health, and (6) they believe that they are capable of making changes.

This study had a number of limitations. The main aim of this study was to develop a scale to measure beliefs about dementia-preventing behaviours, which was very broad in terms of the possible changes participants could have thought about when answering questions. More than one lifestyle and behavioural change was implied for dementia risk reduction. Consequently, it is not clear, which behavioural change individuals were reflecting on when they 
were considering the implication of behavioural change for dementia risk. In addition, if participants did not know what changes were required to reduce their risk of developing dementia (e.g., they did not know that smoking is correlated to a higher risk of developing dementia), they might not have understood what changes the questions were referring to. Moreover, the benefit of behavioural change might not have been clearly established due to participants' unawareness. Therefore, future studies providing information on dementiapreventing behaviours and lifestyle before the completion of the scale should be sought. In addition, future studies examining how these subscales could predict the intention to change lifestyle and health behaviours and whether this intention would be followed by behaviour change itself should also be conducted.

The current study used a convenience sample, which may not be completely representative of the population. Therefore, the psychometric properties of this scale should be further examined in community samples. Furthermore, having no objective assessment of cognition could not guarantee that all participants were free from dementia or cognitive impairment. Therefore, future research should address this limitation and carry out a cognitive testing such as the Mini-Mental State Examination (MMSE) to ensure that we are testing the scale on 50-year-old and older individuals without dementia/cognitive impairment.

Despite these limitations, the current study has contributed to the literature by providing the MCLHB-DRR, which is a first step towards developing more specific instruments to assess particular domains/types of changes. Moreover, as intervention studies based on the HBM have shown increased rates in positive behaviours such as breast cancer screening [30,44], the MCLHB-DRR scale can also be used to increase health-promoting behaviours and lifestyle changes for dementia risk reduction.

The scale can also provide useful information for developing effective interventions. The current study can assist researchers in not only identifying individuals who would benefit most from the intervention but also tailoring intervention programs based on an individual's particular motivations and beliefs. It is likely that different individuals would score differently on each subscale; thus, by identifying specific HBM domains relevant to each individual, tailored interventions are possible and even desirable [45]. For instance, for someone who is low on perceived susceptibility and high on perceived benefits, education focused on the prevalence of dementia may be more effective for changing behaviours and lifestyle than education targeted at the benefits of performing preventive behaviours.

This is the first study known to the authors that develops and assesses the psychometric properties of a scale attempting to understand the beliefs of health and lifestyle behaviours specifically aimed at preventing dementia. The analysis of the psychometric properties of the MCLHB-DRR scale are encouraging and suggest that it is a useful tool to assess beliefs about lifestyle and behavioural changes for dementia risk reduction among middle-aged and older Australians. This tool could be used in intervention studies and surveys aimed at dementia prevention.

\section{Acknowledgements}

S.K. was funded by the Dementia Collaborative Research Centre (DCRC) and the Australian Research Council Centre of Excellence in Population Ageing Research (CEPAR). K.J.A. was funded by the National Health and Medical Research Council (NHMRC), fellowship No.1002560. K.A.S.-C. was funded by the CEPAR (CE110001029). N.C. was supported by the NHMRC, fellowship No. 471501. 


\section{Disclosure Statement}

The authors have no conflicts of interest to declare.

\section{Appendix A}

Motivation to Change Lifestyle and Health Behaviour for Dementia Risk Reduction (MCLHB-DRR) Scale

Perceived susceptibility

Q26.0 My chances of developing dementia are great

Q28.0 I feel that my chances of developing dementia in the future are high

Q29 There is a strong possibility that I will develop dementia

Q30 Within the next 10 years I will develop dementia

Perceived severity

Q37 The thought of dementia scares me

Q38 When I think about dementia my heart beats faster

Q40 My feelings about myself would change if I develop dementia

Q42 When I think about dementia I feel nauseous

Q46 It would be more serious for me to develop dementia than if I developed other diseases

Perceived benefits

Q53 Information and advice from experts may give me something that I never thought of, and may reduce my chance of developing dementia

Q54 Changing my lifestyle and health habits can help me reduce my chance of developing dementia

Q55 I have a lot to gain by changing my lifestyle and health behaviour

Q57 Adapting to a healthier lifestyle and behaviour would prevent dementia for me

Perceived barriers

Q58 I am too busy to change my lifestyle and health habits

Q61 My financial situation does not allow me to change my lifestyle and behaviour

Q62 Family responsibilities make it hard for me to change my lifestyle and behaviour

Q65 Changing lifestyle and behaviour interferes with my schedule

Cues to action

Q126 Being forgetful makes me think I have to change my lifestyle and behaviour

Q70 Having risk factor(s) for dementia makes me think I have to change my lifestyle and behaviour

Q71 Learning more about dementia from the media makes me think I have to change my lifestyle and behaviour

Q72 Knowing family member(s) with dementia makes me think I have to change my lifestyle and behaviour

General health motivation

Q73 Nothing is as important to me as good health

Q74 I often think about my health

Q76 I think I have to pay attention to my own health

Q77 I am concerned about my health

Self-efficacy

Q86 I am certain that I can change my lifestyle and behaviour so I can reduce the risk of developing dementia

Q87 I am able to make differences that will change the risk of developing dementia 
Kim et al.: Development of the Motivation to Change Lifestyle and Health Behaviours for Dementia Risk Reduction Scale

\section{References}

1 Conner M, Norman P: The role of social cognition in health behaviours; in Conner M, Norman P (eds): Predicting Health Behaviour: Research and Practice with Social Cognition Models. Buckingham, Open University Press, 1995, pp 1-22.

2 Adler N, Matthews K: Health psychology: Why do some people get sick and some stay well? Annu Rev Psychol 1994;45:229-259.

-3 Smith TW, Orleans CT, Jenkins CD: Prevention and health promotion: decades of progress, new challenges, and an emerging agenda. Health Psychol 2004;23:126-131.

4 Akbaraly TN, Porter F, Fustinoni S, Dartigues J-F, Artero S, Rouaud O, Touchon J, Ritchie K, Berr C: Leisure activities and the risk of dementia in the elderly: results from the three-city study. Neurology 2009;73:854861.

5 van Uffelen JGZ, Paw M, Hopman-Rock M, van Mechelen W: The effects of exercise on cognition in older adults with and without cognitive decline: a systematic review. Clin J Sport Med 2008;18:486-500.

6 Flicker L, Almeida OP, Acres J, Le MTQ, Tuohy RJ, Jamrozik K, Hankey G, Norman P: Predictors of impaired cognitive function in men over the age of 80 years: results from the health in men study. Age and Ageing 2005; 34:77-80.

7 Abbott RD, White LR, Ross GW, Masaki KH, Curb JD, Petrovitch H: Walking and dementia in physically capable elderly men. JAMA 2004;292:1447-1453.

8 Weuve J, Kang JH, Manson JE, Breteler MMB, Ware JH, Grodstein F: Physical activity, including walking, and cognitive function in older women. JAMA 2004;292:1454-1461.

-9 Scarmeas N, Stern Y, Mayeux R, Manly JJ, Schupf N, Luchsinger JA: Mediterranean diet and mild cognitive impairment. Arch Neurol 2009;66:216-225.

10 Scarmeas N, Stern Y, Tang MX, Mayeux R, Luchsinger JA: Mediterranean diet and risk for Alzheimer's disease. Ann Neurol 2006;59:912-921.

11 Anstey K, Mack H, Cherbuin N: Alcohol consumption as a risk factor for dementia and cognitive decline: metaanalysis of prospective studies. Am J Geriatric Psychiatry 2009;17:542-555.

-12 Anstey K, von Sanden C, Salim A, O’Kearney R: Smoking as a risk factor for dementia and cognitive decline: a meta-analysis of prospective studies. Am J Epidemiol 2007;166:367-378.

$\checkmark 13$ Lu FP, Lin KP, Kuo HK: Diabetes and the risk of multi-system aging phenotypes: a systematic review and metaanalysis. PLoS One 2009;4:e4144.

14 Anstey K, Lipnicki DM, Low LF: Cholesterol as a risk factor for dementia and cognitive decline: a systematic review of prospective studies with meta-analysis. Am J Geriatr Psychiatry 2008;16:343-354.

15 Ferreira MP, Willoughby D: Alcohol consumption: the good, the bad, and the indifferent. Appl Physiol Nutr Metab 2008;33:12-20.

-16 Ownby RL, Crocco E, Acevedo A, John V, Loewenstein D: Depression and risk for Alzheimer disease: systematic review, meta-analysis, and metaregression analysis. Arch Gen Psychiatry 2006;63:530-538.

17 Anstey K, Cherbuin N, Budge M, Young J: Body mass index in midlife and late-life as a risk factor for dementia: a meta-analysis of prospective studies. Obes Rev 2011;12:e426-e437.

18 Gustafson D: A life course of adiposity and dementia. Eur J Pharmacol 2008;585:163-175.

19 Barnes D, Yaffe K: The projected effect of risk factor reduction on Alzheimer's disease prevalence. Lancet Neurol 2011;10:819-828.

20 Richard E, Van den Heuvel E, Moll van Charante EP, Achthoven L, Vermeulen M, Bindels PJ, Van Gool WA: Prevention of dementia by intensive vascular care (PreDIVA): a cluster-randomized trial in progress. Alzheimer Dis Assoc Disord 2009;23:198-204.

21 Lautenschlager NT, Cox KL, Flicker L, Foster JK, van Bockxmeer FM, Xiao J, Greenop KR, Almeida OP: Effect of physical activity on cognitive function in older adults at risk for Alzheimer disease: a randomized trial. JAMA 2008;300:1027-1037.

-22 van de Rest O, Geleijnse JM, Kok FJ, van Staveren WA, Dullemeijer C, Olderikkert MGM, Beekman ATF, de Groot CPGM: Effect of fish oil on cognitive performance in older subjects: a randomized, controlled trial. Neurology 2008;71:430-438.

-23 Willis SL, Tennstedt SL, Marsiske M, Ball K, Elias J, Koepke KM, Morris JN, Rebok GW, Unverzagt FW, Stoddard AM, Wright E: Long-term effects of cognitive training on everyday functional outcomes in older adults. JAMA 2006;296:2805-2814.

24 Lustig C, Shah P, Seidler R, Reuter-Lorenz PA: Aging, training, and the brain: a review and future directions. Neuropsychol Rev 2009;19:504-522.

25 Michie S, Johnston M, Francis J, Hardeman W, Eccles M: From theory to intervention: mapping theoretically derived behavioural determinants to behaviour change techniques. Appl Psychol 2008;57:660-680.

26 Painter JE, Borba CPC, Hynes M, Mays D, Glanz K: The use of theory in health behavior research from 2000 to 2005: a systematic review. Ann Behav Med 2008;35:358-362.

27 Guvenc G, Akyuz A, Acikel CH: Health Belief Model Scale for Cervical Cancer and Pap Smear Test: psychometric testing. J Adv Nurs 2011;67:428-437.

28 Glanz K, Rimer B, Lewis F (eds): Health Behavior and Health Education, ed 3. San Francisco, Jossey-Bass, 2002.

29 Champion VL: Instrument development for health belief model constructs. Adv Nurs Sci 1984;6:73-85. 
-30 Champion VL: Revised susceptibility, benefits and barriers scale for mammography screening. Res Nurs Health 1999;22:341-348.

-31 Gözüm S, Aydin I: Validation evidence for Turkish adaptation of Champion's Health Belief Model Scales. Cancer Nurs 2004;27:491-498.

32 Reynolds KD, Metz DS, Unger J: Health behaviour research and intervention; in Wallace R (ed): Public Health and Preventive Medicine. New York, the McGraw-Hill Companies, 2007, pp 941-942.

33 Seydel E, Taal E, Wiegman 0: Risk-appraisal, outcome and self-efficacy expectancies: cognitive factors in preventive behaviour related to cancer. Psychology and Health 1990;4:99-109.

34 Schwarzer R: Self-efficacy in the adoption and maintenance of health behaviours: theoretical approaches and a new model; in Schwarzer R (ed): Self-Efficacy: Thought Control of Action. London, Hemisphere, 1992, pp 217-243.

35 Kim S: To change or not to change? Determinants of changing lifestyle and health behaviour for dementia risk reduction (unpubl. doctoral dissertation). Canberra, Australia, Australian National University, 2014.

-36 Werner P: Factors influencing intentions to seek a cognitive status examination: a study based on the health belief model. Int J Geriatr Psychiatr 2003;18:787-794.

-37 Galvin JE, Scharff DP, Glasheen C, Fu Q: Development of a population-based questionnaire to explore psychosocial determinants of screening for memory loss and Alzheimer Disease. Alzheimer Dis Assoc Disord 2006; 20:182-191.

38 Kim S, Anstey K, Sargent-Cox K: Motivations and barriers to lifestyle and behaviour change for dementia risk reduction: National Dementia Research Forum. Sydney, Australia, 2011.

39 Byrne BM: Testing for the factorial validity of scores from a measuring instrument (first-order CFA model); Structural Equation Modeling with AMOS: Basic Concepts, Applications, and Programming. New York, Taylor and Francis Group, 2010, pp 97-127.

40 Hu L-T, Bentler PM: Evaluating model fit; in Hoyle RH (ed): Structural Equation Modeling: Concepts, Issues, and Applications. Thousand Oaks, Sage, 1995, pp 76-99.

41 Hu L-T, Bentler PM: Cutoff criteria for fit indexes in covariance structure analysis: conventional criteria versus new alternatives. Struct Equ Modeling 1999;6:1-55.

42 Joreskog KG, Sorbom D: Lisrel 8: Structural equation modeling with the simplis command language. Chicago, Scientific Software International, 1993.

43 Brown MW, Cudeck R: Alternative ways of assessing model fit; in Bollen KA, Long JS (eds): Testing Structural Equation Models. Newbury Park, Sage, 1993, pp 136-162.

44 Vietri V, Poskitt S, Slaninka SC: Enhancing breast cancer screening in the university setting. Cancer Nurs 1997; 20:323-329.

45 Krebs P, Prochaska JO, Rossi JS: A meta-analysis of computer-tailored interventions for health behavior change. Prev Med 2010;51:214-221.

46 Janz NK, Champion VL, Strecher VJ: The health belief model; in Glanz K, Rimer B, Lewis F (eds): Health Behavior and Health Education: Theory, Research, and Practice. San Francisco, Jossey-Bass, 2002, pp 31-44.

47 Cheung GW, Rensvold RB: Evaluating goodness-of-fit indexes for testing measurement invariance. Struct Equ Modeling 2002;9:233-255. 